


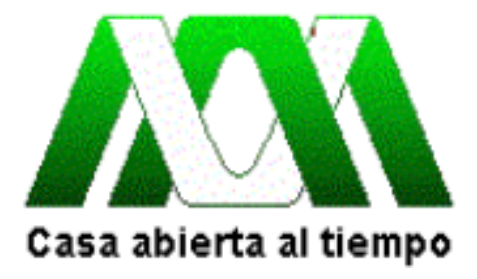

\author{
Universidad Autónoma Metropolitana \\ Unidad Iztapalapa \\ División de Ciencias Sociales y Humanidades \\ Posgrado en Ciencias Antropológicas
}

La producción cultural de la marginalidad urbana: acercamiento a jóvenes del Distrito de Aguablanca en la ciudad de Cali, Colombia.

\author{
Julieth Andrea Narváez Villegas \\ ENSAYO \\ Para obtener el Diploma de Especialización \\ en Antropología de la Cultura \\ Director: Dr. Néstor García Canclini
}

Ciudad de México

Octubre, 2019 


\title{
La producción cultural de la marginalidad urbana: acercamiento a jóvenes del Distrito de Aguablanca en la ciudad de Cali, Colombia.
}

\author{
Julieth Andrea Narváez Villegas
}

\begin{abstract}
Resumen
Este documento busca recuperar el concepto de marginalidad como una categoría práctica útil para comprender la producción cultural en contextos urbanos. Para esto se analizan los aportes y limitaciones del concepto, haciendo énfasis en la necesidad de investigar de manera situada la construcción cultural de la marginalidad. Como recurso se utilizan entrevistas realizadas a jóvenes habitantes del Distrito de Aguablanca en la ciudad de Cali, Colombia.
\end{abstract}

Palabras clave

Marginalidad, cultura, jóvenes, urbano, Cali, Colombia. 


\section{Introducción}

Aunque el fenómeno de la marginalidad ha sido históricamente estudiado desde un paradigma económico, su aparición como concepto a mediados del siglo XX ha despertado el interés del conjunto de las ciencias sociales, multiplicando los esfuerzos para describirlo y caracterizarlo. La incursión de la sociología, la geografía y la antropología en el estudio de los márgenes, nos ha advertido sobre la complejidad de la noción y ha diversificado las aproximaciones teórico-metodológicas a un hecho que hoy por hoy es innegable, a saber, la existencia de segmentos de la sociedad que habitan la periferia -sea esta el "tercer mundo", las zonas rurales segregadas o los cinturones de miseria urbana-, desarticulados de la economía y la cultura dominantes, generalmente empobrecidos y vulnerados, $y$, sin embargo, productores activos de sentido y escenarios paradigmáticos de la hibridación cultural.

Las corrientes que han estudiado el fenómeno de la marginalidad pueden clasificarse, para efectos prácticos, de la siguiente manera (Bassols, 1990; Cortés, 2006; Delfino, 2012; Enríquez, 2007):

Por un lado, encontramos las teorías desarrollistas o de la modernización inauguradas en los años sesenta y adoptadas ampliamente por los organismos económicos internacionales y los gobiernos. Desde este marco, se define la marginalidad como una integración aún no alcanzada por algunos sectores de la población, y se propone combatirla a través de programas que aumenten las oportunidades para acceder a empleos estables y educación, y a través de la apertura 
de mercados competitivos. Este enfoque asume la marginalidad como un producto de los retrasos en el proceso de integración económica de algunos sectores sociales, y supone que puede ser resuelta a partir de intervención, pública o privada, que mejore las condiciones para que personas, grupos sociales o países, puedan desarrollar sus potencialidades.

En segundo lugar, la concepción estructural-económica de la marginalidad, surgida desde la teoría de la dependencia entre las décadas de los sesentas y setentas, analiza este fenómeno como producto del modelo político-económico capitalista, que condena a amplios sectores de la población a la precariedad permanente, a través de una distribución inequitativa de los recursos y de formas de enajenación económica y cultural que conducen a la consolidación de la Masa Marginal (Bassols, 1990). De esta corriente se desprende también, entre los años ochentas y noventas, la conceptualización de los sistemas-mundo y la noción de centro-periferia; herramientas fundamentales para comprender las dinámicas que producen y sostienen las formas de organización económica y social contemporáneas (Wallerstein, 2015).

Una tercera contribución al estudio de estos segmentos sociales, ocurrida durante los años noventa, condujo al florecimiento del concepto de exclusión social. Con este giro muchos pensadores latinoamericanos buscaron poner el acento en el papel del Estado como productor y reproductor de los segmentos marginales, e introducir una visión cultural, ecológica e incluso psicológica del fenómeno (Enríquez, 2007). Sin embargo, esta noción ha mantenido la discusión en términos de inclusión/exclusión al grupo 
social hegemónico, y ha derivado en interpretaciones que, por su diversidad, han sido adaptadas y utilizadas estratégicamente desde todos los frentes de la estructura social, generando confusiones en su definición.

Si bien estas corrientes plantean elementos diferenciales respecto a los actores que participan del proceso de segregación/marginación y las posiciones que estos ocupan, todas analizan el fenómeno desde una visión estructural. Esto quiere decir que tanto las teorías desarrollistas, como la estructural-económica y la perspectiva de la exclusión social, enfocan sus explicaciones en la definición y análisis de lo que Radcliff-Brown (1952) define como entidades unificadas (p.206). Lo anterior significa que estos marcos explicativos, independientemente de la valoración que hacen de las formas de organización socioeconómica dominantes -como positivas y potenciales, o negativas y condenatorias-, analizan el sistema social como un todo en el que existen posiciones, relaciones y formas de interacción bien definidas, diferenciadas y constantes.

Este análisis estructural de la marginalidad no solo es valioso sino absolutamente necesario para entender cómo las distintas manifestaciones de la separación ${ }^{1}$ social responden a dinámicas económico-políticas que van mucho más allá de los individuos que componen cada comunidad o sector marginal. No obstante, si lo que buscamos es acercarnos al punto de vista de aquellos y aquellas que viven la condición de

\footnotetext{
${ }^{1}$ Prefiero utilizar la noción de separación frente a la de exclusión o segregación, pues estas últimas ponen el acento en las entidades que ejercen la exclusión o la segregación. Con el término separación, quiero evocar la existencia de dos entidades activas que por distintas razones toman distancia una de la otra. Esto sin ignorar las evidentes y desiguales relaciones de poder que ejercen unas entidades sobre otras cuando se produce esta separación.
} 
marginalidad diariamente, no podemos confiarnos solo a una definición estructural. Más allá de eso, debemos empeñarnos en comprender la manera en la que la condición de marginalidad se expresa en y a-través-de los individuos y toma distintas formas, dando lugar a relaciones e identidades que mezclan y transforman los discursos estructurales, económicos o étnico-políticos, dándoles, en muchos casos, usos estratégicos.

La intención de retomar el concepto de marginalidad, frente a los conceptos de exclusión o segregación social, radica en el potencial político asociado al primero; en tanto puede convertirse en una categoría ontológica que no remite necesariamente a la acción de un otro. Con esto quiero decir que, cuando denominamos a los actores de la periferia como excluidos o segregados, inmediatamente parecemos remitirnos a una entidad que es la causante de esta condición, y restamos protagonismo a los actores marginales. Es cierto que la posibilidad de señalar los procesos globales -y siempre locales- a partir de los cuales se genera la desigualdad, no es para nada despreciable, pues ha arrojado luz sobre el papel de los actores institucionales y el modelo políticoeconómico capitalista en la profundización de las diferencias sociales; pero también ha parcializado la investigación, privilegiando el análisis económico y una concepción pasiva de los actores marginales.

Un abordaje exhaustivo de la marginalidad nos lleva a tratar de comprender el fenómeno en términos culturales, es decir, en términos de prácticas y significados que surgen desde estos contextos, e involucran concepciones acerca del territorio, la 
historia de la comunidad, las relaciones vecinales, las dinámicas de violencia, entre otras; mucho más allá de la definición estructurante de la incertidumbre económica crónica (Adler, 1998).

Hay que reconocer que en términos de lo cultural resulta difícil establecer límites entre aquello que se encuentra integrado y aquello que permanece al margen, sobre todo si tenemos en cuenta, primero, que las formas de producción y los canales de circulación de los significados se han extendido en la sociedad contemporánea (García Canclini, 2005, 2012); y segundo, que los significados de la vida social no son estáticos, y deben ser comprendidos "como un movimiento muy peculiar de reasociación y reensamblado" (Latour, 2008, p.21). Por lo tanto, estamos obligados a una comprensión dinámica de lo cultural, en la que todos los actores involucrados son participantes activos de la significación, estableciendo intercambios y negociaciones en las que los bienes y las prácticas se transforman constantemente.

Introducir esta perspectiva dinámica en el caso de la marginalidad urbana, implica estudiar las prácticas de separación que ejercen tanto los sectores integrados como los periféricos. Analizar por ejemplo las dinámicas de fisión y fusión (Evans-Pritchard, 1940) que producen la periferias, o las contradicciones que viven los individuos frente a los discursos estructurales y estructurantes que organizan la realidad social al interior de estos grupos (Turner, 1984), es una empresa importante para ampliar la comprensión que hasta ahora tenemos de la marginalidad, a la que la antropología puede contribuir enormemente. 


\section{Convertir la marginalidad en una categoría práctica: un abordaje antropológico.}

Sin duda existen ya aproximaciones antropológicas al fenómeno de la marginalidad que trascienden el estructuralismo. Ejemplo de esto son las investigaciones desarrolladas por Wacquant (2001, 2013, 2015) y Auyero (2010). Ambos autores se interesan en la experiencia de la marginalidad y la manera en la que se construyen las subjetividades en los contextos urbano-marginales. Por un lado Wacquant incluye entre los elementos característicos de la marginalidad la fragmentación de las identidades o disolución de las clases y gremios; la fijación y estigmatización de territorios; la disolución de los significados asociados a los lugares o alienación del espacio; y, por último, la pérdida de un país interno ${ }^{2}$ dónde refugiarse ante la crisis (Gíglia, 2016). Todos estos elementos se refieren a la manera como la marginalidad se materializa en la cotidianidad de los individuos, y pueden ser discutidos a partir del análisis de las narrativas y prácticas identitarias de las personas que conforman estos sectores.

En esta misma vía Auyero (2010) nos propone analizar los dispositivos que moldean las subjetividades de las personas que viven en condición de marginalidad, pero además cómo estos dispositivos son incorporados y transformados desde la periferia para dar lugar a nuevas formas de relación con la economía y cultura dominantes.

\footnotetext{
${ }^{2}$ Con país interno el autor se refiere a los sistemas de significado que soportan la vida social.
} 
Ambos autores enriquecen el análisis de la marginalidad urbana y controvierten las definiciones estrictamente económicas que se han dado tradicionalmente al fenómeno. Sin embargo, vale la pena abundar en estudios etnográficos que contribuyan a entender la experiencia de vivir en los márgenes y que enfaticen en el papel que tienen cada una de las entidades -las integradas y las marginales-, en esta separación.

Sumar datos etnográficos a las investigaciones que diseccionan la marginalidad para concluir, por ejemplo, que las periferias urbanas están sumidas en condiciones de incertidumbre económica crónica, a las que sobreviven gracias a redes de solidaridad recíproca (Adler de Lomnitz, 1998), o que la marginalidad es producto de la desarticulación de algunos sectores sociales a los ritmos económicos dominantes (Wacquant, 2001), o que el estado implementa dispositivos sutiles, y muchas veces explícitos, para moldear la subjetividad de los marginales (Auyero, 2010), no es quizá la vía más enriquecedora para la investigación contemporánea sobre este fenómeno. Es necesario poner el foco en el conflicto, en lugar de redundar, aunque sea innegable, en que la marginalidad es producto de entidades que excluyen y segregan a sectores sociales como parte del sostenimiento de un modelo político-económico productor de desigualdad.

Si bien en el imaginario popular lo marginal parece estar asociado a condiciones de precariedad y miseria, no debemos olvidar que su etimología remite, fundamentalmente, a aquello que se encuentra en el borde, a la orilla, que es fronterizo. Es por lo anterior que considero importante abundar en la investigación sobre la 
experiencia de la marginalidad, más allá de las condiciones estructurales que la producen, que, a pesar de ser innegables, nos hacen pensar en horizontes de transformación distantes y borrosos. Si bien es cierto que las iniciativas localizadas no representan golpes medulares al modelo económico-político dominante, y que los cambios dependen de "la intervención prolongada de muchos actores y la creación y consolidación de instituciones suficientemente poderosas” (Reygadas, 2008; p. 354), ahondar en la comprensión de las dinámicas internas de los sectores marginales discursivas y prácticas-, nos puede llevar a concebir rutas que aceleren el cambio.

El estudio situado de los márgenes, de las tensiones, conflictos y cambios que se producen al interior de estos sectores, nos acerca un poco más a la comprensión del fenómeno y a la construcción de rutas y prácticas que nos permitan hacer frente a la situación y analizar, como lo propone Auyero (2010), ¿qué es lo que hace que las personas que viven en condición de marginalidad toleren y reproduzcan las prácticas y dispositivos que los marginan?

Para esto, resulta de mucha utilidad la propuesta de Mosse (2013) en la que, tras un recorrido por las corrientes que desde la antropología han estudiado el fenómeno del desarrollo, nos invita a pensar en este último como una categoría práctica:

"That is, to understand the way in which development "becomes produced and reproduced as a common sense part of people's understanding of the word and their place within it" and how "the delineation of [development] emerges from, 
and produces, particular historical circumstances, particular culture logics, and finally, particular subjectivities" (Curtis \&Spencer, 2012, p.179)" (Mosse, 2013; p. 230)

Esto significa que, así como en el caso del desarrollo, debemos dejar de pensar la marginalidad como un fenómeno que ocurre por fuera de las experiencias y la agencia de un grupo social, o solo como una categoría de análisis desde la cual caracterizar una estructura socioeconómica determinada. En cambio, la marginalidad, como el desarrollo, debe ser pensada como el producto de las interacciones entre actores que manipulan los discursos y significados dando lugar a configuraciones y prácticas muy diversas, pero, además, como el resultado de la intersección de distintas dimensiones de la vida social.

\section{La construcción cultural de la marginalidad urbana.}

Con el propósito de analizar la experiencia de la marginalidad, este documento retoma entrevistas realizadas a jóvenes habitantes de la zona urbano-marginal ubicada en la periferia oriente de la ciudad de Cali, Colombia, conocida como el Distrito de Aguablanca. Estas entrevistas, llevadas a cabo en el mes de agosto de 2019, en el marco del proyecto ¿Identidades urbano-marginales?: el caso del Distrito de Aguablanca en Cali, Colombia ${ }^{3}$, hacen parte de un acercamiento inicial a las narrativas y prácticas

\footnotetext{
${ }^{3}$ Investigación para optar por el título de Maestría en Ciencias Antropológicas de la Universidad Autónoma Metropolitana - Unidad Iztapalapa, Ciudad de México, 2018-2020. Realizada por Julieth Narváez y dirigida por la Dra. Maria Ana Portal.
} 
identitarias de los jóvenes del sector. La información retomada en este documento incorpora entrevistas a miembros de organizaciones socioculturales y proyectos de intervención gestados desde instituciones públicas, así también, incluye entrevistas a jóvenes que no hacen parte de estos procesos, pero habitan el Distrito de Aguablanca, con distintos niveles de formación educativa que van desde el bachillerato trunco hasta formación profesional a nivel de pregrado concluida.

Establecer límites político-administrativos para lo que se denomina el Distrito de Aguablanca en la ciudad de Cali resulta muy difícil si recurrimos a los documentos oficiales, que utilizan principalmente la figura de comunas para dividir la ciudad. Podríamos decir que el Distrito de Aguablanca se refiere al espacio de urbanización inicialmente autogestionado en la rivera de inundación del Río Cauca iniciado en los años cuarenta y consolidado entre los años setentas y noventas, que incluye en su totalidad a las comunas 13,14 y 15, un segmento de la comuna 16, la comuna 21 de más reciente creación, e incluso algunos de los barrios que hacen parte de las comunas 6 y 7, como lo es Petecuy en sus tres etapas (Ver Imagen 1). 


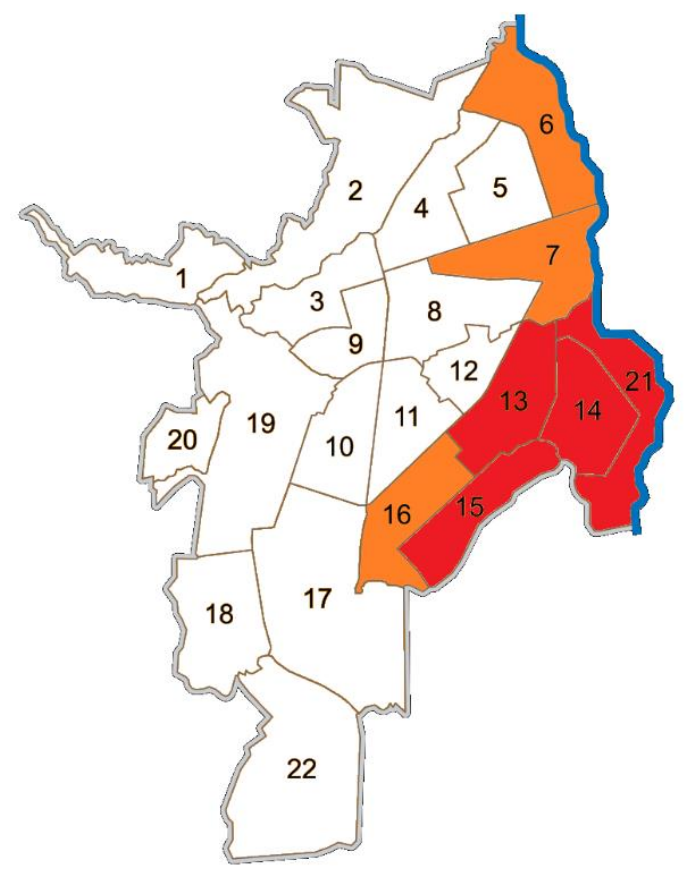

Imagen 1: mapa de la ciudad de Cali tomado de internet e intervenido. En rojo las comunas correspondientes al Distrito de Aguablanca, en naranja aquellas que hacen parte parcialmente del Distrito. Al margen derecho el Río Cauca.

La definición de lo que corresponde geográficamente al Distrito de Aguablanca es mucho más sencilla, como la explica uno de los entrevistados, quien asegura que el Distrito es todo lo que queda entre la autopista Simón Bolivar y el Río Cauca (Ver Imagen 2), y que además está encerrado:

La Simón Bolivar era pa acá era Distrito y pa allá era Cali... es que el Distrito está encerrado. El Distrito la única salida [que tiene] es por el Puente de los Mil Días, o por la Troncal, y ahora está la salida pal'sur, porque antes la otra salida era por la escombrera y la escombrera es un puente de dos carriles. Viene la Simón Bolivar que trae cinco carriles y pasa a dos carriles. Esa era la salida del oriente hacia el sur. (Rocky $\left.14^{4}\right)$

\footnotetext{
${ }^{4}$ El infórmate pidió explícitamente que su seudónimo fuera el de Rocky14.
} 


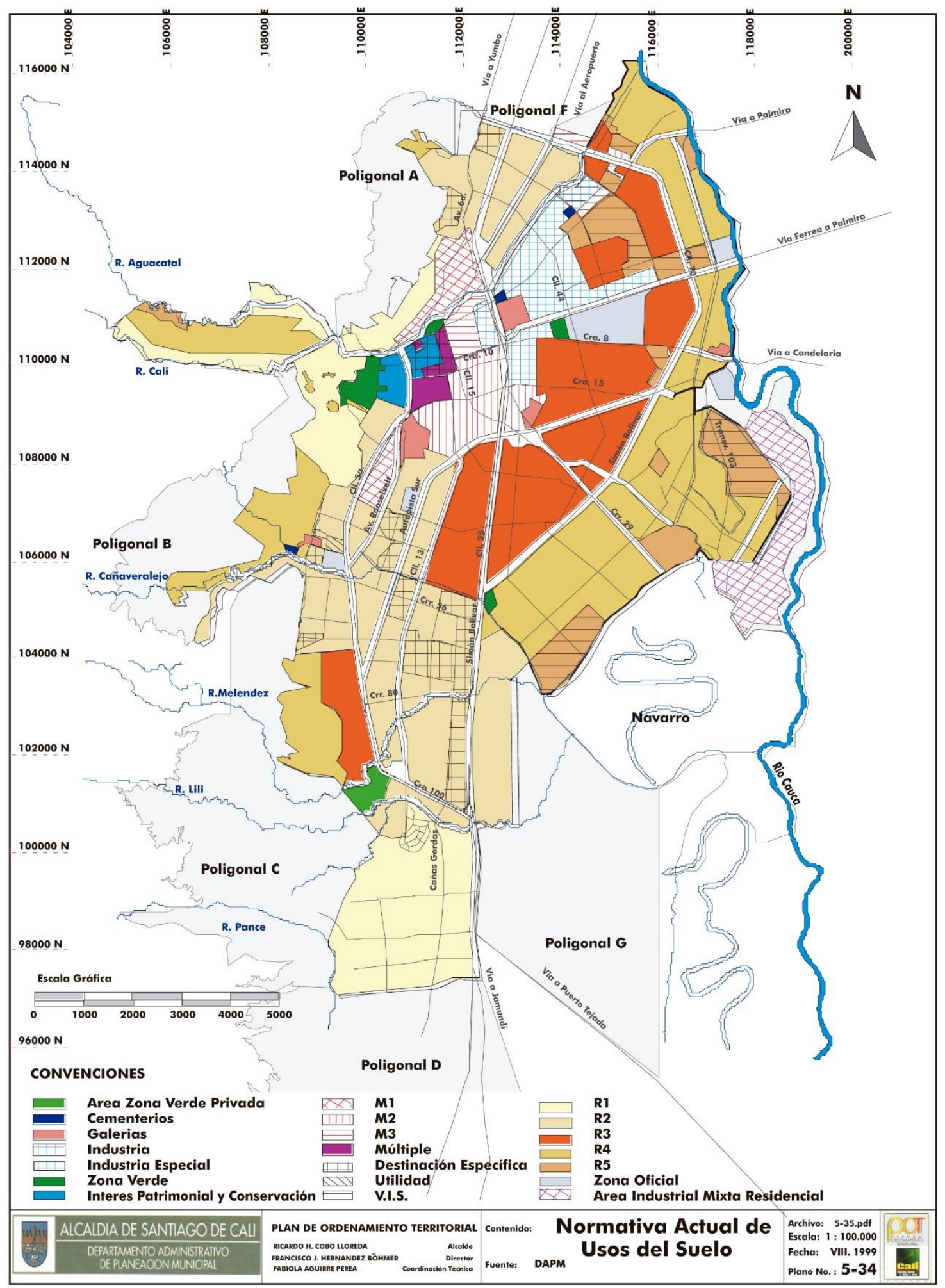

Imagen 2: tomada de Tomado de: https://www.gifex.com/fullsize/2011-08-1714327/Usos_del_suelo_en_Cali.html 
Esta separación concreta e imaginaria del Distrito de Aguablanca y el "resto de la ciudad" es constante entre los entrevistados, y toma distintas formas, que aluden principalmente a la conexión física del oriente con “Cali”, pero también al hecho de que la ciudad integrada resulta ajena a quienes han crecido en el sector:

Cuando no teníamos plata salíamos solo cerca a la casa porque era más barato y no había que pagar taxi, pero empezamos a trabajar y dijimos "vamos a conocer otros sitios", pero... el otro día fuimos por la tercera norte, y entre todos los sitios terminamos escogiendo el que más se parecía a los que hay en el Distrito, que porque los otros eran muy caros, que no nos gustaban, que muy "gomelos". Entonces es lo mismo. (Harany)

Es constante la alusión a "Cali" como si fuera un lugar diferente y alejado del Distrito de Aguablanca, pero también llama la atención la existencia de una gradación de lo que es el Distrito conforme los barrios se acercan a la Avenida Simón Bolivar. Entre los entrevistados, sobre todo aquellos con menores niveles educativos el resto de la ciudad resulta ajena y distante, no ubican con facilidad los barrios más allá del oriente y mucho menos los eventos culturales y artísticos que se llevan a cabo en otros puntos de la ciudad, pero logran ubicarse con mucha facilidad al interior del Distrito, así cómo reconocer cuáles son las zonas por las que se puede transitar, en qué momentos del día y con qué compañía.

¿Dónde están haciendo el Petronio? (refiriéndose al festival Petronio Álvarez, uno de los más importantes de la ciudad)... Lo están haciendo por allá por San Antonio, en Cosmocentro. (Marcos) 
Yo soy de la Sari, y terminé trabajando aquí en el Poblado, aunque los de aquí siempre han tenido "liebres" con los de allá, pero como ya me conocen no hay problema. El problema es cuando salimos a caminar hacia otra parte, casi siempre es mejor agarrar la troncal o la ciudad de Cali, las calles principales, porque entre las cuadras siempre hay quien salga a armarles problema. Ellos también saben, y por eso toca moverse con cuidado. Aquí donde están andan timbrados, echando ojo a ver si les sale alguien de algún lado. (Lizbeth).

Así como los habitantes de la ciudad encapsulan el oriente de Cali bajo el nombre del Distrito de Aguablanca, homogeneizando las características y condiciones de todos los barrios y comunas que ahí se encuentran, los jóvenes del Distrito encapsulan el resto de la ciudad, afirmando por ejemplo que San Antonio -uno de los barrios más antiguos y turísticos de la ciudad- queda junto a Cosmocentro -un centro comercial que se ubica cuatro kilómetros hacia el sur de San Antonio, aunque también en el sector poniente.

Ahora bien, sobre el proceso de poblamiento de las periferias de Cali es necesario tener en cuenta, entre otras cosas, el carácter transitorio que ha tenido la ciudad desde su fundación, en tanto punto de intersección entre el sur del continente, el centro administrativo del país y la salida al mar por la costa de Buenaventura (Vásquez, 1980); además debemos analizar la agudización del desplazamiento y el engrosamiento de los márgenes urbanos entre los años setenta y noventa, en relación al recrudecimiento del conflicto armado y el narcotráfico en el país, así como algunas catástrofes naturales y el debilitamiento del Estado Benefactor (Cabrera, Nieto y Giraldo, 2017). Pero ¿cómo aparece la historia de poblamiento entre los jóvenes entrevistados? 
Sobre este proceso conflictivo y autogestionado de poblamiento del Distrito aparecen numerosas referencias entre los informantes, quienes, sin excepción, aluden a la invasión o la compra de lotes a bajo costo, así como a la migración desde otras zonas del país o la ciudad, para referirse a su llegada al sector. Todos los informantes, de entre 18 y 29 años, se reconocen como una segunda generación de habitantes del Distrito, y narran con algunos detalles la llegada de sus padres al lugar.

Mi mamá llegó de Roldanillo y mi papá de Antioquia, primero llegaron a vivir con unos tíos, luego, cuando se dieron cuenta de las invasiones se vinieron para acá a agarrar un lote. Ahí tuvieron que acampar varios meses en lo que iban consiguiendo el material, porque si se descuidaban o se iban llegaba la policía o llegaban otros más vivos y lo agarraban. (Jhony)

Mis papás primero invadieron en los chorros, pero cuando allá empezó a haber mucha gente se alborotaron y la alcaldía tuvo que asignarles un lote acá en Puertas, para esa época todo estaba vacío y solo se dividían los lotes con cabuya, y cada quien iba trayendo sus ladrillos para montar primero un cuarto y luego ya un baño, y así. Esto no era tan peligroso antes porque todo el mundo andaba en las mismas, construyendo. (Harany)

Mi familia vino de Guapi, primero mi tío y luego se trajo a mi mamá, y así se fueron viniendo todos, aunque todavía tengo familia en Guapi, pero no conozco. (Amalia)

Aunque en todos los casos aparecen referencias a los extensos y difíciles procesos de asentamiento, las reacciones frente a la pregunta por la permanencia a largo plazo en el Distrito de Aguablanca son diversas, e incluso contradictorias entre los mismos jóvenes. 
La gente sigue viviendo aquí porque no tiene plata, usted deles un peso más y se van, todo el mundo se quiere ir. (Rocky14)

Ante esta afirmación otra de las entrevistadas interpela al informante:

¿Y vos por qué no te has ido? Tu familia tiene como irse pa' otra parte, y siempre han dicho que se quieren ir y se quieren ir y no se van. Tuvo que pasar lo que pasó para que se fueran.... La diferencia entre la familia de Rocky 14 y la mía es que para ellos siempre ha sido un peso vivir en el Distrito, siempre se han quejado, que esto tan peligroso, que está lleno de negros, que tanta bulla, pero ahí vivieron como veinte años, es que uno se acostumbra a vivir aquí y es muy difícil irse, uno piensa que no va a poder vivir en otra parte. (Harany)

...porque es que uno ama el lugar donde vive, uno se siente seguro, o sea por más inseguro que sea el barrio uno se siente seguro, porque vos ya conoces quien es el amigo que roba, vos sabes a qué hora podes entrar, a qué horas no, uno se siente seguro. No, yo no me iría, a otro sector puede ser que sí. (Amalia)

Esta última intervención de Amalia, en la que se hace manifiesta la naturalización de la violencia en el Distrito es sólo una de las múltiples referencias a la inseguridad como un de los factores que definen a la zona, pero además nos enseña cómo los habitantes del sector han creado estrategias de adaptación a estas dinámicas, incorporándolas en su cotidianidad.

Cuando recién llegamos me agarraron ahí en el callejón dos manes, me pusieron un fierro y me dijeron “¿Vos de qué equipo sos?”, y yo estaba cagado porque yo que iba a saber de qué equipo eran los manes, pero pues uno va con toda, con lo que es, sin mente, y les mostré que estaba tatuado, "no hay mas papi", y ya me pararon y en la buena. Por eso mi papá pintó la casa de verde, también por el finado. (Jhony) 
No se te hace un peso, pero ¿por qué nos tenemos que ir temprano? Porque a tu casa no se puede entrar tarde ¿cierto? Allá ni entran los taxis. ¿No nos bajó el taxi el otro día? Nos bajó allá en la quince. ¡Nos bajó! ¡nos bajó el taxi!, que “¿pa dónde van?”, no “que pa’ la casa de Harany", no que "aquí los dejo"... [risas]. (Rocky 14, interpelando a Harany luego de su intervención sobre la comodidad con la que ella y su familia viven en el Distrito de Aguablanca.)

Esta conversación abre una discusión entre Rocky 14 y Harany, que evidencia la existencia de una división simbólica entre quienes habitan el Distrito y quienes están más integrados a la ciudad. Recupero la interacción completa porque la considero de mucho valor:

Harany: Bizco pero es que él se cree que salió del Distrito porque se fue a vivir a Villacolombia (risas)

Rocky14: Villacolombia es del puente de los Mil Días pa'ca.

Julieth (entrevistadora): ¡No jodas que te fuiste! ¿Por qué?

H: Cuente ¿por qué se fue del Distrito?

R14: Porque esos negros son muy bullosos.

H: Le ofrecieron plomo y le tocó irse de allá bizco.

R14: Mentiras que esos negros son muy bullosos. Yo ya vivo del puente de los Mil Días hacia acá.

J: Sí, yo sé dónde queda Villacolombia.

R14: Ya no estoy en el Distrito.

$\mathrm{H}$ : Entonces él dice que ya no está en el Distrito, y que no va a volver.

R14: Yo ya por allá no voy porque eso es una olla. (Risas)

H: Sabiendo que él vivía allá al pie del 9 de enero en el hueco ese, entonces él dice que no, que ya allá no se mete (risas)

J: Villacolombia también es caliente.

R14: ¡O sea, marica! Allá un corte de pelo vale doce mil pesos marica. (Imitando el acento estereotípico de la clase alta)

J: ¿Pero si es distinto o es la misma mierda? 
R14: ¡No! ¿Cómo se le ocurre? Allá sí vive gente.

$\mathrm{H}:$ ¿Y en el otro lado qué vive entonces?

R14: Pues esa... gente también... pero esa gente diferente.

Otro de los ejes fundamentales para analizar las experiencias de marginalidad en el Distrito de Aguablanca podría estar asociados a la composición étnico-racial del oriente de Cali. Sobre esto, debemos reconocer el impacto de la culminación del proyecto "Ferrocarril del Pacífico" en los años veinte, que conectó a la ciudad de Cali, promesa industrial de la época, con el litoral pacífico y las comunidades afrocolombianas, que hasta ese momento se habían dedicado a la extracción minera en condiciones de semi-esclavitud (Lasso, 2013; Vásquez, 1980).

Como nos enseña Arboleda (1998), la consolidación de la industria azucarera en el Valle del Cauca y el florecimiento comercial de la ciudad de Cali durante los años sesentas y setentas impulsaron los procesos migratorios desde distintos puntos del suroccidente colombiano. Estas migraciones ampliaron la disponibilidad de mano de obra a bajo costo en labores intersticiales de la vida económica y engrosaron las zonas periféricas de la ciudad, principalmente las laderas correspondientes a las comunas 18 y 20, y posteriormente la rivera de inundación del Río Cauca, de más difícil ocupación por la composición de sus suelos deslavados.

Si bien todos los entrevistados aluden al proceso de poblamiento autogestionado, las referencias a una pertenencia étnico-racial o al carácter fundamentalmente afrodescendiente del oriente de Cali, aparece de manera ambigua 
en las conversaciones. Son sobre todo los jóvenes que hacen parte de organización socioculturales o políticas los que han elaborado reflexiones acerca de la composición étnica del sector:

El trabajo que hacemos en el círculo de mujeres es reconocer el tipo de violencias a las que nos enfrentamos en estos contextos, sobre todo siendo mujeres negras, porque más allá de la violencia intrafamiliar hay una violencia estructural contra las comunidades negras. (Debay)

...mi papá, nosotros nos fuimos, por inseguridad nos fuimos tres años a vivir a Ibagué, vivimos en Ibagué tres años pero yendo y viniendo. Vivíamos en Ibagué, vivíamos en el Espinal, no conocíamos a nadie... Sí, no conocíamos a nadie por allá y nos fuimos pero ¿hace qué?, como tres años, cuatro años, sí como hace cuatro años llegamos otra vez acá a Cali... nos toco que regresarnos porque la estadía allá es muy dura, la gente es muy dura también, son muy racistas... Son muy racistas, demasiado. (Amalia)

Entre los jóvenes que participan en el proyecto TIP (Tratamiento Integral de Pandillas), entrevistados en el marco de una de las actividades realizadas por Amalia, no resultó casi ninguna referencia relacionada con su pertenencia étnica. Sólo en el caso de Dayana, al hablar sobre aquello con lo que se identifica, menciona las trenzas como parte de sus características. Pero las trenzas solo relacionadas con su sueño de tener una peluquería. El resto de los jóvenes hablan de su pertenencia a equipos de futbol, del Gravity Bike, y frecuentemente de sus relaciones de amistad y pareja, atravesadas siempre por sentimientos de desconfianza y recelo, a diferencia de sus relaciones familiares, vertebradoras de sus vidas. 
...que obviamente no todo el que se acerque a mi alrededor obviamente confío en esa persona, ¿si me entiente?, y que sí... ¡epa! (Dayana 2)

\section{Conclusiones.}

Los acercamientos a los jóvenes que viven en el Distrito de Aguablanca, expuestos en el apartado anterior, funcionan como elementos para tratar de responder a la pregunta sobre cómo se configura culturalmente la condición de marginalidad entre las nuevas generaciones que habitan las periferias urbanas. Aunque muchos de los discursos estructurales, relacionados con la explosión industrial de la ciudad y la conexión con el litoral pacífico nos permiten construir una idea de la conformación de estos sectores, las narrativas de los entrevistados amplían nuestra mirada sobre la experiencia de la marginalidad.

Esta información nos muestra la importancia de reconocer las agendas a las que responden los distintos entrevistados en función de dos elementos: primero, su vinculación a organizaciones socioculturales o políticas y su participación en proyectos de intervención; y segundo, su nivel educativo. Analizar estas narraciones requiere que venzamos la visión romántica de las comunidades marginales, que suelen ser caracterizadas como comunitaristas y armónicas (Ferguson, 2005; Hames, 2007), entendiendo no solo que los niveles de separación de la ciudad integrada o ciudad central son relativos a la posición que ocupa cada sujeto en la estructura social, sino que además son cambiantes, y que las relaciones entre los distintos individuos y segmentos 
de los grupos marginales son conflictivas, coyunturales y sobre todo, tienen un enorme potencial creativo y transformador que debemos comprender.

De manera general podemos rastrear en todas las entrevistas una relación ambigua de pertenencia y rechazo a los sectores que se habitan. Si bien, como nos menciona Wacquant (2001) existe una disolución de las identidades que se evidencia por ejemplo en la ausencia de referencias a la composición étnico-racial de los sectores, no debemos pasar por alto la importancia que adquiere este componente en los discursos de quienes realizan intervenciones en el sector, quienes parecen estar interesados en recurrir a la historia de la migración y la vulneración de las comunidades afrocolombianas, como un eje que permita articular y cohesionar a la comunidad. Podemos asumir entonces, como una primera conclusión, que existe un nuevo impulso de las organizaciones y colectivos culturales en el Distrito de Aguablanca, que busca consolidar una identidad periférica a través de actividades políticas y artísticas que reivindican principalmente la pertenencia étnica. Incluso a nivel institucional se ha fortalecido el discurso étnico desconociendo los procesos de hibridación cultural que han vivido las nuevas generaciones de habitantes del DAB.

Respecto a relación que establecen los jóvenes con el territorio que habitan resultan llamativas las constantes alusiones al proceso de poblamiento y a la existencia de una división entre lo que corresponde al oriente de Cali y a la ciudad integrada muchas veces denominada como "Cali". 
Así, podemos decir que la manera en la que los jóvenes se posicionan frente al territorio se presenta como ambigua, encerrada entre una experiencia de pertenencia y rechazo, que, al tiempo que señala la distinción entre ambos sectores y la dificultad para desenvolverse en el sector integrado, añora la huida de la periferia, que se reconoce como violenta y hostil. Sin embargo, el hecho de ser un habitante del Distrito de Aguablanca se convierte también en una forma de construir una subjetividad relacionada con la fortaleza, la resiliencia y una especie de "honor" que se configura a partir de una historia de migraciones y superación de dificultades, lo que se expresa en constantes referencias a la familia como respaldo frente a la vida.

Lejos de la idea de que estos jóvenes han perdido un país interno (Wacquant, 2001), podemos decir que este nuevo sistema de significados que se debaten entre la historia familiar de migración y violencia, la oposición a una ciudad integrada que es ajena e indiferente, y al mismo tiempo el distanciamiento de la cultura dominante. Podríamos suponer que estos jóvenes establecen una relación arbitrariamente hostil con lo que podría denominarse la ciudad integrada o ciudad central, que se expresa a través de lenguajes y estéticas propias de la periferia, a través de los cuales buscan equilibrar las relaciones de poder frente a una estructura social que es excluyente. Su relación con la ciudad central es instrumental, en la medida en que de ella deriva la mayor parte de su sustento.

Finalmente es importante señalar la importancia de ampliar la investigación sobre la experiencia de la marginalidad ahondando en cuatro ejes que parecen ser 
vertebradores de esta condición: uno territorial, relacionado con la significación del espacio y la construcción de fronteras físicas y simbólicas; uno étnico, presente de distintas maneras en las narraciones y prácticas de los jóvenes; uno económico, dado el reconocimiento que tienen los jóvenes de la precariedad económica como un común denominador de los habitantes del sector; y un último eje asociado a las formas de relación comunitaria, romantizado en muchas investigaciones.

Como vemos, esta primera aproximación nos conduce a replantear las preguntas que nos permitan ahondar en la experiencia de la marginalidad, más allá de los discursos estructurales: ¿Qué sentido toma la condición de marginal entre los habitantes de la periferia urbana? ¿Se reconocen, acaso, desde esta categoría? ¿Cómo se expresa esa condición de marginalidad? ¿Cómo se intersectan la dimensión socioeconómica, histórica y étnica en los habitantes de los sectores urbano-marginales? ¿Cómo producen, reproducen y/o transforman su condición de marginales? ¿Qué relaciones establecen con la sociedad integrada? ¿Qué relación construyen con el territorio?

En síntesis, lo que he tratado de exponer a lo largo del documento es la necesidad de profundizar en el estudio de la marginalidad trascendiendo la visión estructuralista tradicional -aunque sin perder de vista sus enormes aportes-, y analizar la marginalidad como una categoría práctica (Mosse, 2013), es decir investigando cómo los individuos y grupos sociales que componen la "ciudad marginal" -porque la marginalidad contemporánea ya no es una condición menor-, en tanto actores, 
entienden, producen, reproducen y transforman su condición de marginales, a partir de discursos y prácticas en las que se intersectan distintas dimensiones de la vida social; todo esto buscando, desde el trabajo etnográfico, entender la experiencia de la marginalidad, con miras a acelerar las transformaciones y la reducción de las asimetrías sociales. 


\section{Bibliografía.}

Adler de Lomnitz, L. (1998). Cómo sobreviven los marginados. Siglo XXI editores: México.

Agudelo, C. (2001). El pacífico colombiano: de remanso de paz a escenario estratégico del conflicto armado. Cuadernos de desarrollo rural No. 46, 7-37.

Arboleda, S. (1998). Le dije que me esperara, Carmela no me esperó. Universidad del Valle. Cali, Colombia.

Auyero, J. (2010). La política de los pobres: las prácticas clientelistas del peronismo. Cuadernos argentinos manantial: Argentina.

Auyero, J. y Berti, M. (2013). La violencia en los márgenes: Una maestra y un sociólogo en el conurbano bonaerense. Katz Editores: Argentina.

Bassols, M. (1990). “La Marginalidad urbana: una teoría olvidada”. Revista Polis Anuario de Sociología, n. 90, 181-198. Recuperado de: http://dcsh.izt.uam.mx/cen_doc/cede/POLIS/1990/Polis-2005-303.pdf

Bourgois, Philippe [1989] (1994) Banano, etnia y lucha social en Centro América, Departamento Ecuménico de Investigaciones, San José, pp. 15-23, 27-36, 177-204. 
Bourgois, Philippe [1995] (2010) En busca de respeto. Vendiendo crack en Harlem, Siglo XXI, Buenos Aires, pp. 31-73.

Cabrera, M., Nieto, L. y Giraldo, R. (2017). Santiago de Cali, paisaje urbano y constitución de una ciudad subjetiva. En: Entramado. Julio - Diciembre, 2017. vol. 13, no. 2, p. 158 -170. Doi: http://dx.doi.org/10.18041/entramado.2017v13n2.26203

Cortés, F. (2006). Consideraciones sobre la marginación, la marginalidad, marginalidad económica y exclusión social, Papeles de Población, 047, 71-84. DANE (2016). Cali en Cifras 2016. Recuperado de: http://www.cali.gov.co/planeacion/publicaciones/138164/cali-en-cifras/

Delfino, A. (2012). La noción de marginalidad en la teoría social latinoamericana: surgimiento y actualidad. Universitas Humanística, No.74, 17-34.

Enríquez, P. (2007). De la marginalidad a la exclusión social: un mapa para recorrer sus conceptos y núcleos problemáticos. Fundamentos en humanidades, año VIII, No. 1, 15/2007, p. 57-88.

Ferguson, James (2005) "Anthropology and its evil twin: "development" in the constitution of a discipline”, en M. Edelman y Angelique Haugerud (eds.) The Anthropology of development and globalization. From classical political economy to contemporary neoliberalism, Blackwell Publishing, Malden, pp. 140-154. 
García Canclini, N. (2005). Diferentes, desiguales y desconectados. México: Gedisa. (2012). “De la cultura postindustrial a las estrategias de los jóvenes" en García Canclini, Néstor; Cruces, Francisco y Urteaga, Maritza. Jóvenes, culturas urbanas y redes digitales. México: Ariel.

Germani, G. (1962). Política y sociedad en una época de transición. De la sociedad tradicional a la sociedad de masas. Buenos Aires: Paidos.

Giglia, A. (2016). Marginalidad, precariado y marginalidad avanzada: definiciones teóricas y realidades empíricas desde distintos contextos socio-espaciales en la ciudad de México. Territorios, 35, 59-80. Doi: dx.doi.org/10.12804/territ35.2016.03

González, J. (2012). Mundos populares entre el desplazamiento y el poblamiento: memorias e interculturalidades en el Distrito de Aguablanca de Cali. Revista Científica Guillermo de Ockham. Vol. 10, No. 2. 13-28.

Lasso, P. (2013). Cuando se vive el desarraigo. Educación y desplazamiento forzado: una mirada desde el Distrito de Aguablanca, Cali, Colombia. Revista Guillermo de Ockham Vol 11 No. 2.35 - 51.

Mosse, D. (2013). “The Anthropology of International Development”, Annual Review of Anthropology, vol. 42, pp. 227-246. 
Reygadas, L. (2019). Crítica del dualismo crítico. El retorno de los enfoques esencialistas en el análisis de la cultura. Sociológica, año 34, número 96, enero-abril de 2019, pp. 73 -106. Doi: http://www.scielo.org.mx/pdf/soc/v34n96/2007-8358-soc34-96-73.pdf

(2008). La apropiación : Destejiendo las redes de la desigualdad. Rubí (Barcelona): Anthropos Editorial ; México: Universidad Autónoma Metropolitana Iztapalapa. Doi: http://sgpwe.izt.uam.mx/files/users/uami/ana/La_apropiacion_LR.pdf Urrea, F. \& Murillo, F. (1999). Dinámica de poblamiento y algunas características de los asentamientos populares con población afrocolombiana en el oriente de Cali. Ponencia presentada al Observatorio socio-político y cultural sobre desplazados, migraciones internas y reestructuraciones territoriales. Centro de estudios sociales, facultad de ciencias humanas, Universidad Nacional de Colombia, Bogotá, 5, 6 y 7 de mayo de 1999.

Urrea, F. y Quintín, P. (2000). Segregación urbana y violencia en Cali: trayectorias de vida de jóvenes negros del distrito de Aguablanca. En Centre de la Vielle Charité (organizador), Séminaire International: guerre, mobilité et territorialité. Marseille, Francia. Recuperado el 24 de marzo de 2010, de http://bibliotecavirtual. clacso.org.ar/ar/libros/colombia/ cidse/segregacion.pdf 
Vásquez, E. (1980) Ensayo sobre la historia urbana de Cali. Cali: Universidad del Valle.

Wacquant, L. (2015) Las dos caras de un gueto. Ensayos sobre marginalización y penalización. Buenos Aires: Siglo XXI.

(2013) Los condenados de la ciudad. Gueto, periferias y Estado. Buenos

Aires: Siglo XXI.

(2001) Parias urbanos. Marginalidad en la ciudad a comienzos del milenio. Buenos Aires: Manantial. 
UNIVERSIDAD AUTÓNOMA METROPOLITANA

DIVISIÓN DE CIENCIAS SOCLALES Y HUMANIDADES DEPARTAMENTO DE ANTROPOLOGÍA

CONSTANCIA DE EVALUACIÓN DEL ENSAYO

PARA LA OBTENCIÓN DEL DIPLOMA EN LA

ESPECIALIZACIÓN EN ANTROPOLOGÍA DE LA CULTURA

\begin{tabular}{|c|c|c|}
\hline DIA & MES & AÑo \\
31 & 10 & 2019 \\
\hline
\end{tabular}

ALUMNA: NARVÁEZ VILLEGAS JULIETH ANDREA

MATRICULA： 2183800162

TRIMESTRE 19-P

DIRECTOR: NÉSTOR RAÚL GARCÍA CANCLINI

LA ALUMNA PRESENTÓ EL ENSAYO TITULADO:

La producción cultural de la marginalidad urbana: acercamiento a jóvenes del Distrito de Aguablanca en la ciudad de Cali, Colombia.

OBTENIENDO LA CALIFICACIÓN DE:

WUWERSBDAD AUTONGRA METROPOLTAR

UPXDAD GXE IZTAPALAPA

Cassa abierta al tiempo

04 NOV LUIY

APROBAR $(x)$<smiles></smiles>

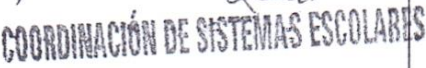

DIRECTOR DEL ENSAYO

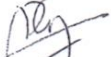

DR. NÉSTOR RAÚL GARCÍA CANCLINI
NO APROBAR ( ) 